\title{
Elites and Culture: Social Profiles in the Cultivated Population
}

\section{Antonio Ariño Villarroya}

University of Valencia, Spain

\section{Ramon Llopis-Goig}

University of Valencia, Spain

\begin{abstract}
Since the 1990s, the central references of the sociology of cultural practices have been the theoretical frameworks developed by Pierre Bourdieu and Richard A. Peterson around the concepts of distinction and omnivorousness. This article is based on these frameworks; it revises them together with those of Donnat and Lahire and postulates that the terms of cultural classification and especially those of the upper classes (distinguished and omnivorous) require revision. The article also claims that there are diverse socio-cultural profiles due to the fact that there is never a single logic of differentiation of tastes, and that the results of the present research demand a new conceptual framework capable of showing the operation of diverse logics of differentiation and hierarchy.

In order to do this, an analysis of the socio-cultural profiles of the cultivated groups in Spanish society is carried out on the data obtained from the Survey of Cultural Habits and Practices in Spain 2018/19. This work proves the existence of three types of cultivated population - classical, modern and syncretic - with notable differences in their cultural interests and practices, as well as in their underlying sociodemographic features and aesthetic logics, and concludes by posing the need to delve into the latter in what it defines as the study of cultural practice regimes.
\end{abstract}

\section{Keywords}

cultural participation, elites, music, social profiles, Spain

\section{Corresponding author:}

Ramon Llopis-Goig, University of Valencia, Department of Sociology and Social Anthropology, Faculty of Social Sciences, Avd. de los Naranjos 4b, Valencia, 4602I, Spain.

Email: ramon.llopis@uv.es 


\section{Introduction}

In the main works published since the beginning of the 21 st century, on the sociology of cultural practices, there are two interpretative frameworks, two authors, two texts and two conceptual objects, which are taken as central references. The authors are Pierre Bourdieu and Richard A. Peterson; their most quoted texts are La Distinction (1979) and 'Understanding audience segmentation' (1992); the key concepts: distinction and legitimacy, on the one hand, and omnivore and tolerance, on the other. These concepts intend to provide an answer to the same kind of problem: the nature of the relationship between social positions and lifestyles, social structures and symbolic systems and, more specifically, between dominant classes and distinguished culture on the one hand and omnivorous culture on the other.

For Bourdieu, between social space and lifestyle, social classes and symbolic patterns, there is a relationship of homology and he claims that the dominant class is the natural place of distinction and that high culture is a legitimate symbolic marker of the dominant class (Bourdieu, 1979; Bourdieu and de Saint Martin, 1976).

Likewise, Peterson (1992), claims that according to the data obtained from a 1982 survey, the American upper classes did not conform to 'pure' or snobbish tastes, but were also 'omnivorous' and therefore appreciated 'the lowest prestige' music such as country and western.

Subsequent research has shown that social class and/or status, based on occupation and educational capital, is of great importance in what concerns the distribution of cultural preferences and practices and that, therefore, the logic of distinction, although metamorphosed, endures (Bennett et al. 2009; Blasius et al., 2019; Coulangeon, 2011; Lahire: 2004; Lizardo and Skiles, 2016a). It is also difficult to find a publication that has not registered a transformation of the kinds of culture on offer and the types of tastes and practices, given the fact that a great majority of individuals mix, combine, and hybridize diverse and even opposed genres (Donnat, 1991, 1994; Chan, 2010, 2019; GarcíaÁlvarez et al., 2007; Lambert, 2019).

However, concentrating only on these two conceptual frameworks has prevented the inclusion of complementary or alternative contributions, in particular those of Olivier Donnat and his thesis on eclecticism and those of Bernard Lahire and his theory on dissonance, which point toward a greater complexity not only in the relationship between cultural preferences and social positions, but also in the forms of cultural participation in all the segments of society and, especially, among socio-cultural elites.

We claim, based on numerous studies from Wilensky (1961), through Gans (1974), to Friedman and Reeves (2020) that: (a) the terms of cultural classification and especially those of the upper classes (distinguished and omnivorous) need to be revised; (b) that there are diverse socio-cultural profiles because they never operate a single logic of differentiation of tastes and that these vary both by interest, behaviour and gender preferences as well as by socio-demographic features; and (c) that the results of the present research demand a new conceptual framework capable of displaying the operation and interaction of diverse logics of differentiation and hierarchy in society as a whole.

Given the fact that publications have concentrated on the cultural patterns of the upper classes over others, we are also going to study the cultural profiles of the sociocultural 
elites detected in the society of Spain, based on the Survey on Cultural Habits and Practices 2018/2019 (hereinafter, EHPCE-2018/2019), with the aim of verifying the existence or nonexistence, of diverse aggregations in this category.

Aware of the robust evidence on cultural inequality, we have decided, from the outset, to use a more neutral, common term with the same meaning in English (cultivated), French (cultivée) or Spanish (cultivado), to designate the social category that maintains a relationship of high interest through almost all cultural practices, the realization of a great variety of them, the possession of knowledge and skills (educational level), and 'accumulation' of activities and 'involvement in culture' (Donnat, 1994). This term was already used by Bourdieu (1968) in his first texts when talking about dispositions, skills and habitus.

First, we will present the theoretical framework, addressing the characterization of the cultural universe of the upper classes, taking as main reference the four authors already mentioned. In the empirical part, once the population group considered as 'cultivated' has been identified, the research tries to examine the main characteristics of this group, verify the existence of internal diversity, but also the sociodemographic features that differentiate the various groupings and the possible aesthetic logics that explain such differences. Finally, we provide an analysis of their preferences in terms of genres in the field of music. The article closes with a section of discussion and conclusions, in which the concept of cultural participation regime is introduced and defined as a possible proposal to overcome the objections raised to the current research.

\section{Theoretical Framework}

We are going to review in a synthetic manner, the four models quoted, regardless of their greater or lesser influence in the academic field: distinction, eclecticism, omnivorousness and dissonance. We will follow the historical sequence of their publications.

In Bourdieu's extensive and complex work La Distinction (1979) and other texts (1984 and 1989; with Saint Martin, 1976), the author proposes a theory of lifestyles, through an ethnography of French society, which distances from Kant, Veblen and the mass society theory. Taste is social, not innate; it is structural and objective, not necessarily conscious; it is relational, rather than substantial. Bourdieu registers and describes three basic types of taste in French society in the 1960s: distinguished or legitimate (dominant class), pretentious or medium (middle classes), and popular (classes deprived of capital). These classifications are based on the overall volume of capital possessed, but when Bourdieu incorporates the composition of capital (economic and cultural) and its trajectory, he discovers the existence of fractions of this capital within the dominant class and the middle classes.

Although Bourdieu does not carry out an identification and classification of the variety of tastes existing within each class, systematically pointing out the category corresponding to each fraction, he does show how the volume and species of capital possessed, as well as the trajectory of its accumulation, produce differences. 
The publication of La Distinction marked a Copernican shift in the analysis of the relationship between social space and lifestyles. Its influence still remains powerful, because it contains fertile and indispensable contributions and because its analysis does not only allow us to grasp cultural plurality (three styles of distinction or structures of consumption in the dominant class), but also its dynamism, based on the dialectic of distinction and pretension.

However, despite offering a framework of multidimensional analysis, what predominated in Bourdieu's work was the differentiation and dual contrast between tastes of freedom and tastes of necessity (Bourdieu, 1984: 56). Consistent with this thesis, Bourdieu maintains that all class fractions, however different they may be, 'are variants of the same fundamental relationship with necessity . . . and that they have in common the search for the exclusive appropriation of legitimate cultural goods and the benefits of the distinction that this appropriation provides' (Bourdieu, 1984: 175), and that all agents run in the same direction, towards the same goals, the same properties, 'those that are marked for them by the group that occupies the first position in the race' (Bourdieu, 1984: 163).

The revision and criticism of this approach has been based both on challenging the rigidity of the theoretical model and on incorporating the growing evidence on the transformation of taste criteria. The need for an open approach has been synthetically expressed in numerous publications during the period spanning the 1980s and the 1990s (Donnat, 1994; Donnat and Cogneau, 1990; Griñon and Passeron, 1989). Publication of Peterson's (1992) work, 'Understanding audience segmentation', would substantially change the dynamics of the debate. But, before presenting such a turn, it is necessary to fix two relevant aspects of Bourdieu's vision which are often ignored: (a) likes are also dislikes and (b) the modality is more important than the content.

Bourdieu claims that tastes unite and separate, that they are the practical affirmation of an inevitable difference and that, not coincidentally, when they have to be justified, they are affirmed entirely in a negative way, through the rejection of other tastes. The popular classes have no other function in the system of aesthetic positions than that 'to serve as a foil, a negative reference point, in relation to which all aesthetics define themselves, by successive negations' (Bourdieu, 1984: 57).

However, symbolic goods are neither static or objective, nor are tastes inevitably anchored to certain goods. The former are defined relationally and contextually; the latter are not identified by what is done (reading, watching, eating, etc.), but by the way in which they are consumed. The uniqueness of the mode of appropriation is what makes it possible to love the same things differently and to love different things in the same way. Consequently, there are strategies of distinction, social uses of cultural goods that, through aesthetization, "transform the "vulgar" artifacts abandoned to common consumption . . . into distinguished and distinctive works of culture' (Bourdieu, 1984: 283). This thesis allows Bourdieu to recognize processes of popularization, devaluation and vulgarization. In studying the variations of taste of the middle classes, for example, he recognizes the existence of two types of eclecticism: the forced one, characteristic of the autodidact, and the elective or savant one of the aesthetes, "who use the mixing of genres and the subversion of hierarchies as an opportunity to manifest their all-powerful aesthetic disposition' (Bourdieu and de Saint Martin, 1976: 37). 
It is precisely the examination of cultural eclecticism in France that constitutes Olivier Donnat's main contribution. From 1990 to 1994, with data from government departments' surveys, Donnat published several texts and reports in which he distanced himself from the theory of cultural legitimacy, while pointing out the unequivocal persistence of cultural inequalities and their relationship with social class (Donnat, 1994, 2003, 2004, 2011). For Donnat, the 'highest' phenomena of the 1970s and 1980s are found in the rise of youth culture and eclecticism, which are clearly manifested in the musical domain, but also in all the others (Donnat, 1994; Donnat and Cogneau, 1990).

In the first published study on the evolution of French cultural practices, using data from ministerial surveys since 1973, Donnat argues that the major event of that period is eclecticism. This thesis will be developed latter (1994 and 2004). In these works, Donnat constructs what he names 'cultural universes'. These consist of knowledge, tastes and practices that, being sufficiently homogeneus and stable, allow the for the identification of different types of categories of population. It describes seven universes, showing the impossibility of defending the existence of a strict homology between cultural universes and social positions. Among the more culturally involved middle and upper classes, Donnat distinguishes three different types: the classical cultivated (reading books, heritage visits, attending the theatre and classical music concerts); the modern cultivated (around the image-sound pair); and the branché universe, connected or eclectic.

The organizing principle of eclectic tastes is their ability to associate activities or genres of books, music or performance that, in the eyes of the theory of legitimacy, appear remote or irreconcilable. The eclectic mix genres cross the boundaries of different forms of cultural expression, and combine with ease classical and modern forms. 'The eclectic', is an expert in separating the 'good grain from the straw' and, therefore, requires the gathering of many resources 'in terms of cultural capital, and the availability and proximity of the cultural capital on offer' (Donnat, 1994: 343; 2004: 91). They not only have great knowledge but also a capacity to conciliate tastes that 'a priori are hardly ever compatible' for the theory of legitimacy; and their wide range of knowledge 'allows them to [carry out] more numerous and original combinations than those of their elders' (Donnat, 2004: 92).

Around the same time, Richard A. Peterson published the earlier-mentioned article in the USA (Peterson, 1992; Peterson and Kern, 1996; Peterson and Simkus, 1992) where he registers a shift in the aesthetic tastes of the upper classes and states that snobbery has become residual. According to his data, $64 \%$ of the high-status population no longer follow the model of the aesthetically exclusive snobs but shows an appreciation for various forms of leisure and cultural activities in addition to the 'refined classical arts'. A 'perfect snob' would be an individual who excludes any manifestation that is not defined as high culture. A 'perfect omnivore' would be an individual who, in addition to classical music, also 'likes all other types of music'.

The term omnivorousness designates a new aesthetic pattern, antithetical to snobbishness, which is open, tolerant and inclusive; it presupposes the existence of clear boundaries between legitimacy and illegitimacy, which the omnivore crosses, and is the aesthetics of consumers with a high level of education and material privilege. Furthermore, despite Peterson's little attention to explaining the meaning, it can be said that the omnivore gains status 'knowing about, and participating in (that is to say, 
by consuming) many if not all forms'; they participate 'more and more often in most kinds of leisure activities' and may display a range of quite different tastes 'as the circumstances demand'.

In subsequent publications, Peterson modified relevant aspects of this vision. In 1996, he equates omnivore with eclectic and qualifies that the omnivore does not like everything indiscriminately; rather, omnivores practice an openness to appreciating everything; he adds that omnivorousness could constitute a new rule of distinction, adapted to the growing predominance of the new business-administrative class and the necessity of showing respect for the cultural expressions of others (Peterson and Kern, 1996). In 1997, Peterson talks about 'cosmopolitan omnivorousness'. In 2002, he states that omnivorousness 'is an expression of the criteria of distinction' and that it is not centred 'on what one consumes but on the way the items are understood' (Peterson, 2002: 37). In 2004, he still maintains that 'omnivority' is essentially a phenomenon of elite status, but at the same time acknowledges that there has been a 'radical transformation of cultural capital' and that different types of omnivority with different social bases could coexist at the same historical moment (Peterson, 2004: 158). In 2005, he accepts that there can also be a lowbrow omnivorousness and that, ultimately, omnivorousness would be a phenomenon that can be measured by the openness or breadth and volume of taste. Finally in the writings he carried out together with Rossman (Peterson, 2005; Peterson and Rossman, 2008; Rossman and Peterson, 2015), Peterson emphasized 'the provisional character' of his interpretation, the 'instability' of the phenomenon when analysing it longitudinally and, above all, the character of 'methodological artefact', inviting 'to the precaution on the triumphalism of the omnivore's ascent' (Rossman and Peterson, 2015: 10), cautions already pointed out by others (Brisson, 2019; Lahire, 2004; Van Eijk, 1999, 2000, 2001; Van Rees et al., 1999; Warde et al., 2007).

None of this has prevented the thesis from becoming the dominant paradigm since it was first formulated. Four positions can be distinguished in the subsequent literature: (a) those who, using different methods, have recorded the existence of ominvorousness and its different modalities in various countries (Katz-Gerro, 2002; Peterson, 2004, 2005 for a comprehensive bibliography); (b) those who have considered the thesis of omnivorousness as an attack on Bourdieu's theory of legitimacy without being able to refute it (Gayo-Cal, 2016; Jarness and Friedman, 2017; Johnston and Bauman, 2007; Johnston et al., 2019); (c) those who maintain that their contribution is nothing more than a 'displacement', 'reconfiguration' or 'metamorphosis' of the cultural profile of the elites, which adapts the theory of distinction to new contexts and times (Coulangeon, 2003; Maguire, 2016; Ollivier, 2008; Warde and Gayo-Cal, 2007); and finally, (d) those who understand that, although they are two different frameworks, they are reconcilable or compatible (Bennett et al. 2009; Blasius et al., 2019; Flemmen et al., 2019; Friedman and Reeves, 2019, 2020; Holbrook et al., 2002; Jarness, 2015; Khan, 2011; Lizardo, 2014; Lizardo and Skiles, 2013, 2016a, 2016b).

In our view, much of this literature has ignored, first, the weak construction of the object that is embodied in the (in)definition of the term 'omnivore', a mere zoological metaphor (Gayo-Cal, 2016; Lahire 2004: 255). Second, the assimilation and confusion of omnivores and eclectic types, whereby the terms have become synonymous, has 
become very common (Bellavance, 2008; Coulangeon, 2003, 2005; de Vries and Reeves, 2020; Johnston and Bauman, 2007; Johnston et al., 2019; Lizardo and Skiles, 2013 Ollivier, 2008; Ollivier and Gautier, 2007). Third, a reductionist interpretation of the so-called 'univore' and a lack of knowledge of all anthropological literature on syncretism or hybridization in the USA (Denny, 1957) and in Latin American popular cultures (García Canclini, 1990; Gruzinski, 1999).

For Bernard Lahire, he does not dispute the existence of cultural inequalities or social distinction based on culture, but instead appears interested in studying the individual as a plural social being. In his magnificent work La Culture des Individus (Lahire, 2004) and various articles (e.g. Lahire, 2008) he focuses on investigating what this plural individual is like. He observes that most individual cultural profiles $(75.8 \%)$ are dissonant, with a greater or lesser tendency toward legitimacy, and that individual cultural heterogeneity is the predominant and most generalized pattern. He also finds two types of consonant profiles, one of high and another of low legitimacy. The consonants at the top, which can also be considered ascetical, snobbish or elitist ("who do not do what they do not love and do not love what for them is considered to be of low legitimacy'), are 3.8\% (Lahire, 2004: 191). The higher intellectual cadres and professions, intermediate professions, and people over 45, are those who are most likely to belong to this group and the number of people who accumulate the highest legitimacy would be irrelevant in statistical terms.

After this brief overview, we can establish three main conclusions:

1. The central terms - distinction and omnivorousness - lack a precise definition. Bourdieu does not supply a proper definition of 'the distinguished' as a social category, since the distinction is at the same time a general social logic, the logic of difference, and the meaning of life or the legitimate culture for the higher classes, 'the natural locus for distinction', as 'they possess monopoly of ease and assurance'; the term 'omnivores' by Peterson is no more than a weak metaphor to designate an accommodative trend and the dissonance of Lahire does not designate a concrete group or category, but a dynamic of the great majority. With the exception of the precedent cited in Bourdieu, only Donnat speaks of a 'cutivated' category. The 'cultivated' are characterized by certain dispositions and competences, acquired formally and informally, and are characterized by a significant level of accumulation of cultural capital. Within this category, the 'eclectic' has the possibility of expressing the power of his/her aesthetic disposition that allows him/her to consciously control a kind of 'code of codes'. (Bourdieu and de Saint Martin, 1976: 37).

2. What and how. The study of the operationalization of omnivorousness shows that some authors have used volume as the determining criterion; others have used variety/heterogeneity/voracity (including the transgression of borders) in combination. However, in accordance with Bourdieu's approach, the determining criterion is not what interests, is practised or consumed, but how it is done. The rule or principle that organizes the combinations of interests, genres and practices is the determining factor (Bourdieu and de Saint Martin, 1976, 1978; Peterson and Simkus, 1992); the formal definition of aesthetics has more relevance than 
the substance (Bennett et al., 2009; Coulangeon, 2011; Daenekindt and Roose, 2014; Friedman et al., 2015; Holt, 1997; Jarness, 2015; Katz-Gerro and Sullivan, 2010; Lizardo and Skiles, 2016b).

3. The plurality of logics in the organization of tastes. It is not only Donnat and Lahire who have recognized the existence and persistence of social and cultural hierarchies and the relevance of the logic of distinction. So have Peterson and his followers. Therefore, the extensive literature used agrees that the hierarchical logic of distinction exists, persists, is transformed and produces legitimate tastes, because dominant groups have a greater capacity to accumulate resources or cultural capital in all its forms (knowledge, preferences, dispositions, competences and practices) and a greater ability to adapt to contexts where there is an imperative towards openness and tolerance and a need to 'camouflage' traditional elitism (Coulangeon and Duval, 2014; Jarness, 2013, 2015; Roueff and Robette, 2014).

But many authors insist that there are also other logics: Donnat pointed out the distinction between classic and modern, eclecticism and generational logic (youth culture); other authors have added collective identities, with their multiple variations (Bellavance, 2008, Bennet et al., 2009; Glevarec and Pinet, 2009, 2017; Katz-Gerro, 2006; KatzGerro and Sullivan, 2010). Now, since the 2010s, there has been talk about emerging cultural capital (Prieur and Savage, 2013; Savage et al., 2015) and authenticity-seeking (Friedman and Reeves, 2020).

\section{Method}

The empirical basis of the research comes from the EHPCE-2018/2019 which consisted in a sample of 15,455 personal interviews of people aged over 15 and living at home. The geographical context covers the entire national territory. The fieldwork was carried out from March 2018 to February 2019 and the information was collected through personal visits. The sampling error, for a $95 \%$ confidence level and a $p=q=0.5$ (in the simple random sampling assumption), was $\pm 0.84 \%{ }^{1}$

Since the main objective of this work is to characterize the cultivated elites in Spanish society in order to ascertain their internal heterogeneity in relation to their cultural interests and practices, stylistic preferences and socio-demographic features, it was necessary to develop a sequence of analysis in several stages. First, the segment of the population that we have defined as the 'cultivated population' was identified, as it is this group that is the focus of the research. Second, its internal composition was examined through the analysis of conglomerates. Third, once the clusters were identified, we proceeded to examine their socio-demographic characteristics (chi-square test), their main cultural practices (binary logistic regression) and their stylistic preferences (chi-square test and analysis of correspondence).

It should be noted that the variables used as input for the analysis of conglomerates came from the application of the principal component analysis technique (PCA) to a battery of cultural interests, while those introduced as independent variables in the binary logistic regression also came from the application of the PCA, but in this case to a set of 
Table I. Population groups according to the number of the cultural activities carried out.

\begin{tabular}{lrrrl}
\hline & $\mathrm{n}$ & $\%$ & Average & SD \\
\hline Low (less than 7 activities) & 2878 & 18.6 & 3.8 & 1.665 \\
Medium-low (from 7 to II) & 3172 & 20.5 & 9.1 & 1.412 \\
Medium (from I2 to I5) & $265 \mathrm{I}$ & 17.2 & 13.5 & 1.114 \\
Medium-high (from I6 to 2I) & 3599 & 23.3 & 18.4 & 1.706 \\
High (22 or more): cultivated & 3155 & 20.4 & 25.9 & 3.386 \\
Total & 15,455 & 100.0 & 14.5 & 7.848 \\
\hline
\end{tabular}

Source: own elaboration on EHPCE-2018/2019.

variables that referred to cultural practices. The presentation of the results in the following section includes only those tables that we have considered strictly necessary for the objectives of the work, although interested readers may find the rest of the statistical information in the supplementary data given in the Appendixes.

\section{Results}

The first task consisted of identifying the population that we are going to consider 'cultivated', initially, the population group with the greatest volume of cultural participation. To this end, we elaborated an index of accumulated cultural participation, which included the 47 variables of cultural practices. This index was compiled by assigning a value $=1$ to the time performance frequencies specified in Appendix 1 and a value $=0$ to the lower ones. The distribution of percentages obtained, once the indicator was prepared (Appendix 2), revealed that $4.7 \%$ of the Spanish population enjoyed two or fewer cultural activities, while $3 \%$ enjoyed 30 or more, with 40 being the maximum number of activities indicated by some interviewees. In order to classify the population according to the number of cultural practices, percentiles 20,40, 60 and 80 were calculated, standing at 7,12, 16 and 22 activities, respectively (Table 1). The 3,155 people who stated that they enjoyed 22 or more cultural activities, therefore comprise the group with the highest number of activities, and this represents $20.4 \%$ of the sample. This category is restrictively described as cultivated.

The segment identified as cultivated enjoys an average of 25.9 cultural activities; obviously well above those carried out by the rest of the groups. Similarly, as might be expected, cultivated people are also more interested in culture, in any of the 25 areas on which the EHPCE 2018/2019 collects information (Appendixes 3 and 4).

Having identified the cultivated population group in a volumetric sense, the next step was to check the structure and the degree of internal heterogeneity of the group. To do this, it was necessary to identify, beforehand, the general structure of the cultural interests of the Spanish population, counting on the 25 aforementioned items, to which the technique of the principal component analysis with Varimax rotation was applied. The analysis provided a significant model at 99.9\% (Bartlett test), with a high adjustment $(\mathrm{KMO}=0.939)$, and yielded five components that together explained $70.5 \%$ of the variance (Appendix 5). These five components bring together interests in performing 
Table 2. Final cluster centres of cultivated people.

\begin{tabular}{lccr}
\hline & Cluster I & Cluster 2 & Cluster 3 \\
\hline Interest in the performing and classical arts & -1.00278 & 0.58877 & 0.76504 \\
Interest in the museum and heritage & $0.488 I 7$ & 0.75497 & -0.07027 \\
Interest in reading & 0.49082 & 0.77615 & 0.05053 \\
Interest in cinema and audiovisual & 0.47787 & -0.31420 & 0.70757 \\
Interest in music & 0.42480 & 0.42168 & 0.16575 \\
$\mathrm{~N}$ & 987 & 1273 & 895 \\
$\%$ & $31.3 \%$ & $40.3 \%$ & $28.4 \%$ \\
\hline
\end{tabular}

Source: own elaboration on EHPCE-2018/2019.

and classical arts; museums and heritage; reading; cinema and audiovisual contents; and finally, music.

The next step was to check the internal homogeneity of the cultivated population in relation to these. To do this, a cluster analysis was carried out following the suggestions of Hair et al. (1999), when they point out that it should consist of a first phase of determining the number of clusters and a second phase of cluster optimization. In the first, a hierarchical method (Ward's method and Euclidean distance squared) was applied to determine the appropriate number of clusters and their initial centres and, in the second, the $k$-mean optimization method from the initial centres.

The most appropriate solution offers three groups. Before examining the characteristics of each conglomerate, the validity of the classification obtained was checked using the analysis of the variance technique (ANOVA) and the discriminating analysis. The ANOVA of the solution in three conglomerates revealed that the variability between groups exceeded the intra-group variability $(p<0.001)$. On the other hand, when performing a discriminating analysis using as a dependent variable the membership to the three conglomerates created with the $k$-means method and, as independent variables, the five components of the cultural interests, the percentage of correctly assigned cases amounted to $95.3 \%$. Finally, the distance between the centroids (Euclidean distance) also obtained positive results since the coefficients obtained ranged from 1.532 to 1.937 , indicating that the conglomerates are clearly differentiated.

Once the validity of the three clusters typology was checked, we present their final centres in Table 2. The first cluster stands out essentially for having the highest musical interests, as well as high scores in reading, museums and heritage and cinema/audiovisual, although in these three, its score is not the highest. It is the group furthest away, by far, from the performing and classical arts, which is why the name that best suits it is cultivated moderns. The second conglomerate shows the highest interest in reading, museums and heritage, with high interest in performance and classical arts and music, while it records the lowest score in interest in cinema and audiovisuals. It can be considered as a group of cultivated classics. The third conglomerate shows the highest interest in both performance and classical arts and in cinema and audiovisual contents. These two components contributed the most to defining the previous conglomerates in relative terms, as they recorded the most negative score in each of them. The fact that 
they appear simultaneously with the highest levels in this third conglomerate justifies the denomination of cultivated syncretics, as they try to combine two disparate universes of activities. They also score lowest in interest in reading and in interest in museums and heritage. We call them syncretic and not eclectic because, as we have shown in the theoretical framework, eclecticism involves a strategic selection of 'the best' from different universes. The available data do not allow us to know that this is the case, while syncretism only involves the combination of heterogeneous elements.

Next, we performed a bivariate analysis in order to obtain a sociodemographic characterization of the clusters. The variables considered were sex, cohort, educational level and employment situation (Table 3). Those responsible for the design of the questionnaire did not include occupational status among the variables of the questionnaire, which is why they could not be included in the analyses presented in this research, although it is a crucial form of stratification in the literature on cultural consumption.

The Chi-square tests carried out show that the differences between the cultivated population and the rest of the population are statistically significant in all cases $(p<0.001)$, although in the case of sex, the intensity of the association is certainly lower $(p<0.05)$. The same happens when examining the degree of association between these sociodemographic variables and the belonging to each of the three groups of cultivated people, being in all cases statistically significant $(p<0.001)$. With regard to each of the three clusters, the following can be noted:

- Cultivated moderns have a higher proportion of men and young people. While men represent $50.3 \%$ among the cultivated population and $48.1 \%$ of the rest of the population, they are $61.5 \%$ of their own cluster. The weight of the younger cohorts clearly exceeds that of the latter in both the whole cultivated and in the rest of the population. Of the three types, it is the one that offers a lower percentage in higher education, but in employment status, the category 'student' stands out.

- Among the cultivated classicals, there is a higher proportion of women. It is the oldest conglomerate with the highest proportion of people who have university degrees, none other than $52 \%$, when for the non-cultivated population is $14.6 \%$; and it presents the lowest percentage among the student population.

- The cultivated syncretics are distinguished by a greater presence of women, similar to the classicals. Their age distribution is the most balanced and most similar to that of the whole cultivated population. Along with the cultivated classics, they also offer the highest percentages of the retired population.

In any case, beyond the aspects that differentiate the three types of cultivated people, we should not ignore the fact that, in general, they are much younger, have a higher level of education (more than twice the percentage of the general population) and are more often in an active situation (working or studying) than the population as a whole (Table 3).

Therefore, we offer a study of the patterns of cultural participation of the three conglomerates through the application of binary logistic regression analysis. The variables with which it is carried out come from a main component analysis previously achieved on the sample of the population categorized as cultivated (Appendix 6). The rotation method was also the Varimax normalization with Kaiser. The analysis shows 10 components that 


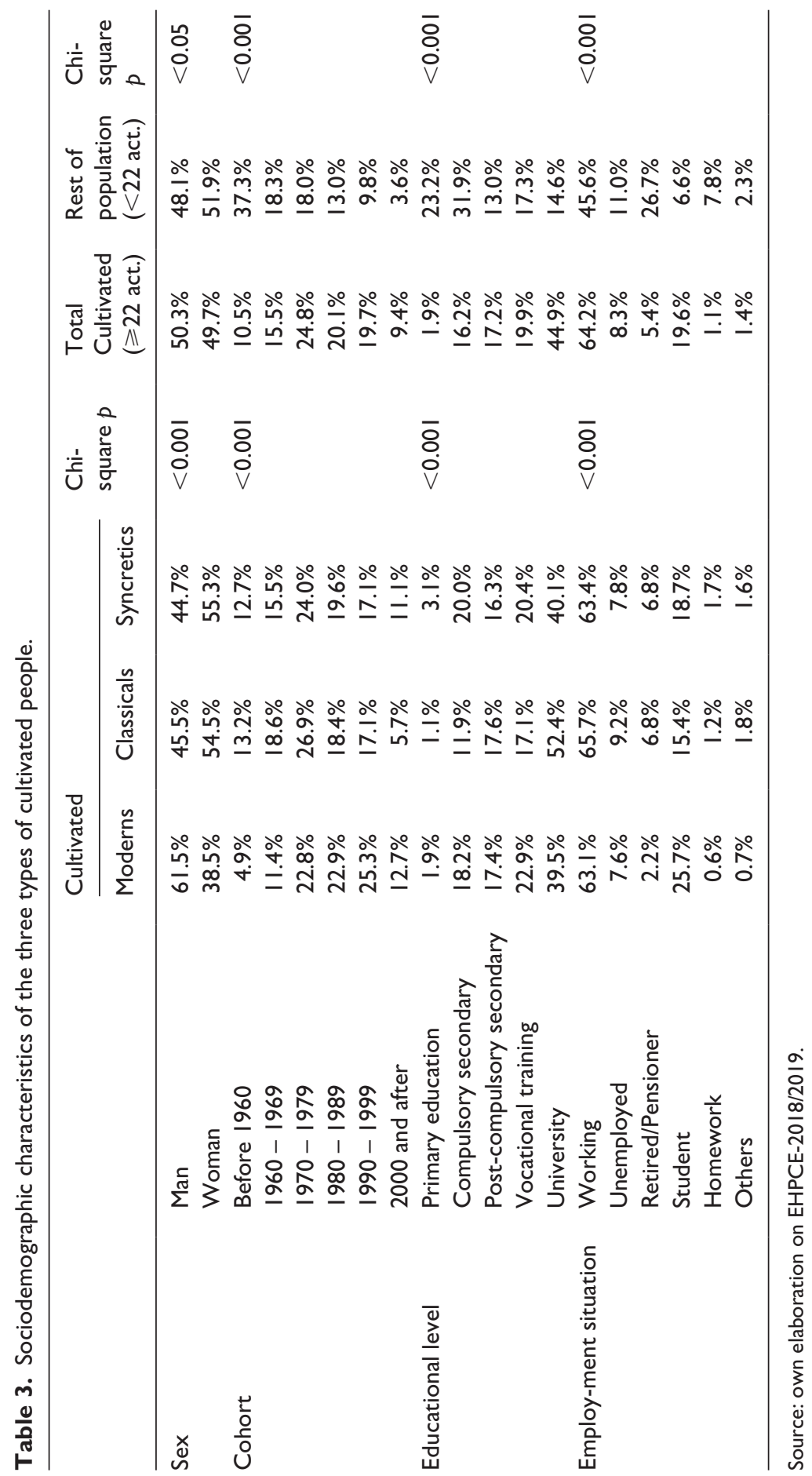


explain $56.1 \%$ of the variance and reach a KMO of 0.676 . The identified dimensions refer to museums and heritage visits; attendance to performing arts shows and classical music concerts; internet connection and reading related to work and studies; consumption of films and series; use of tablet for both leisure and work/study purposes; reading cultural magazines; reading newspapers versus reading books for leisure, attending libraries, using a computer and having internet connection for leisure; and finally, listening to music and attending contemporary music concerts.

Therefore, three binary logistic regression analyses have been implemented to determine the probability that the practices are carried out by each of the three cultivated clusters (Table 4). Among the cultivated moderns, the probability of attending performance arts and classical shows, reading magazines and, to a lesser extent, visiting museums and heritage sites, is very low. However, it is the conglomerate which increases most the probability of having internet connection for work or study reasons, as well as for reading newspapers, listening to music and attending modern music concerts. Belonging to the cultivated classicals cluster decreases the probability of consuming films and series, using the tablet, listening to music and attending pop or rock musical concerts, but increases the probability of connecting to internet for leisure reasons and visits to museums and heritage sites and, to a much greater extent, reading magazines, attending libraries and attending performing arts and classical concerts. Finally, in the case of cultivated syncretics, the probability of attending libraries and museums and heritage sites, as well as internet connection and computer use for any reason, decreases, but the probability of reading books for leisure, listening to music and attending concerts of contemporary music, as well as consuming films and series and attending performing arts and classical concerts increases.

The last step in the study of the features of the cultivated population goes into the analysis of the genres to which the cultural participation of the cultivated population is most associated. The aim is to reach the most detailed level that surveys of this kind allow for, and it is especially relevant because this is the level on which the thesis of the omnivorous consumer is based, who is a fan of classical music and opera, but is also interested in popular genres.

The cultivated population shows a greater listening habit of practically all the musical genres they are asked about in the survey (Table 5), including both those of a more minority nature, such as classical music and jazz - where it doubles the rest of the population - and others of a more popular nature, such as singer-songwriters and flamenco. The only cases where the differences in favour of the cultivated population are not statistically significant are in the case of flamenco, new flamenco, zarzuela and other musical genres. On the other hand, the non-cultivated population exceeds the cultivated population only in the musical genres referred to as melodic song and other Spanish folklore (other than flamenco), but the differences are statistically significant only in the first case. More generally, in 15 of the 21 musical genres examined, the differences detected between the three types of cultivated people are statistically significant, which constitutes empirical evidence of the stylistic differences among them.

That said, information included in Table 5 allows us to state that:

- Cultivated moderns present lower than average percentages of both the cultivated population and the rest in four genres: melodic song, other Spanish folklore, opera 


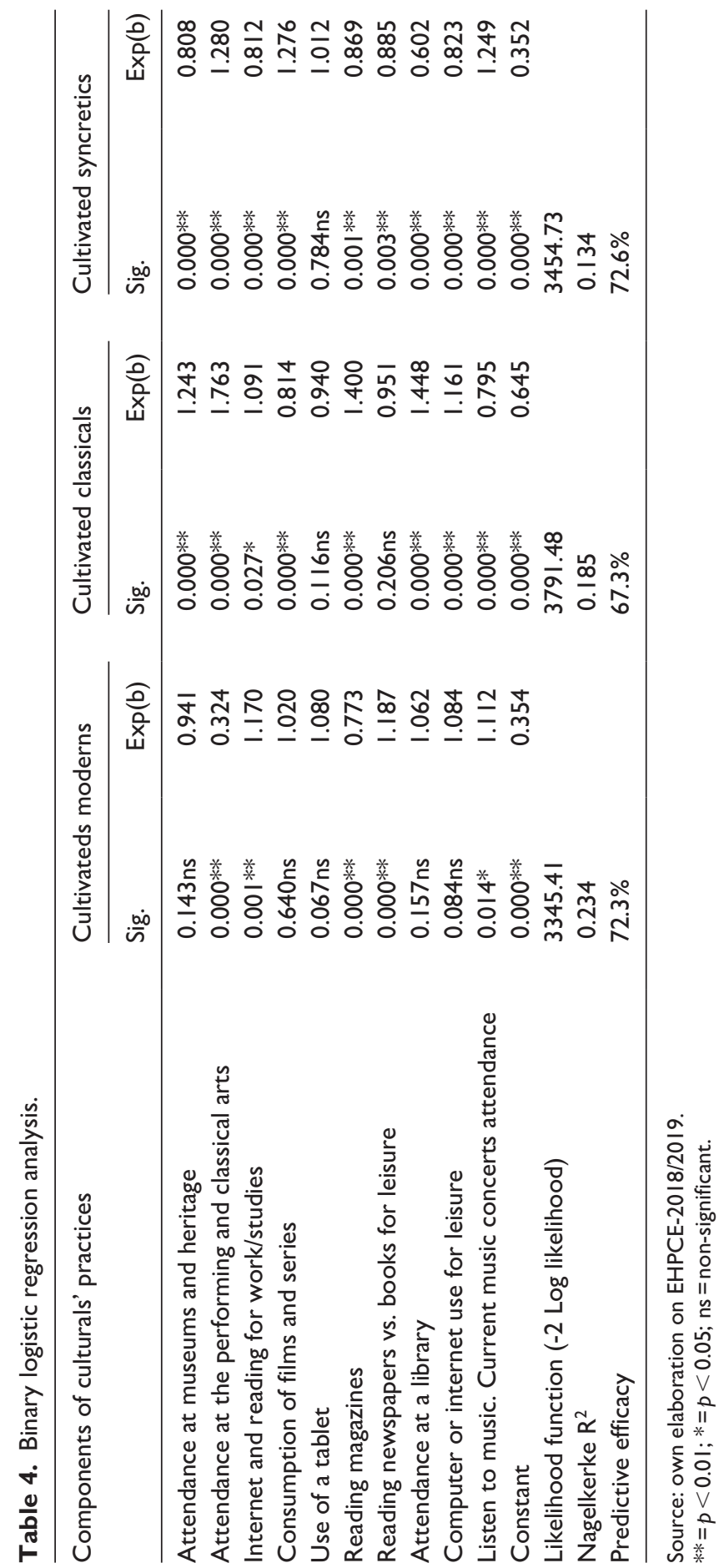




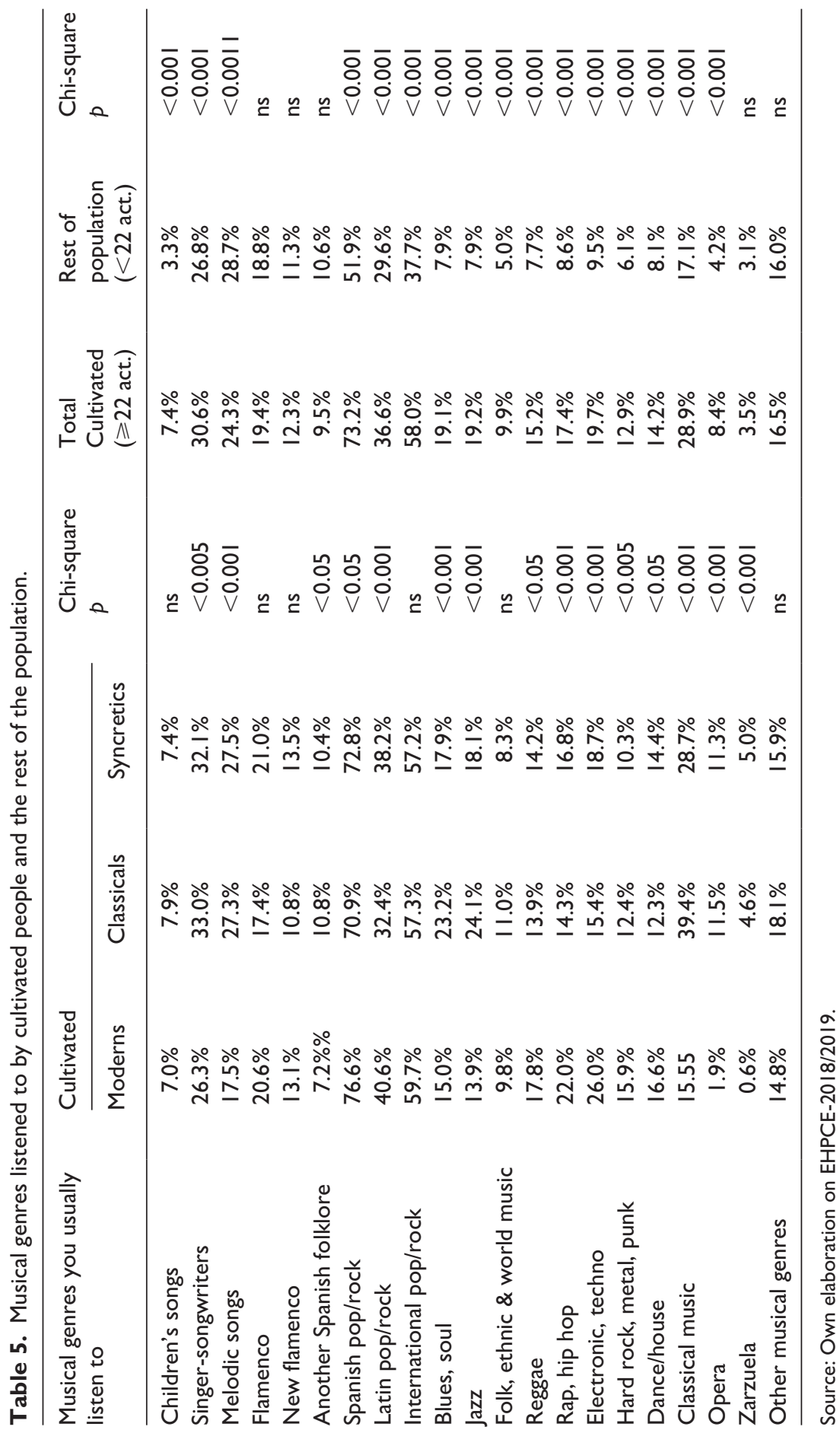




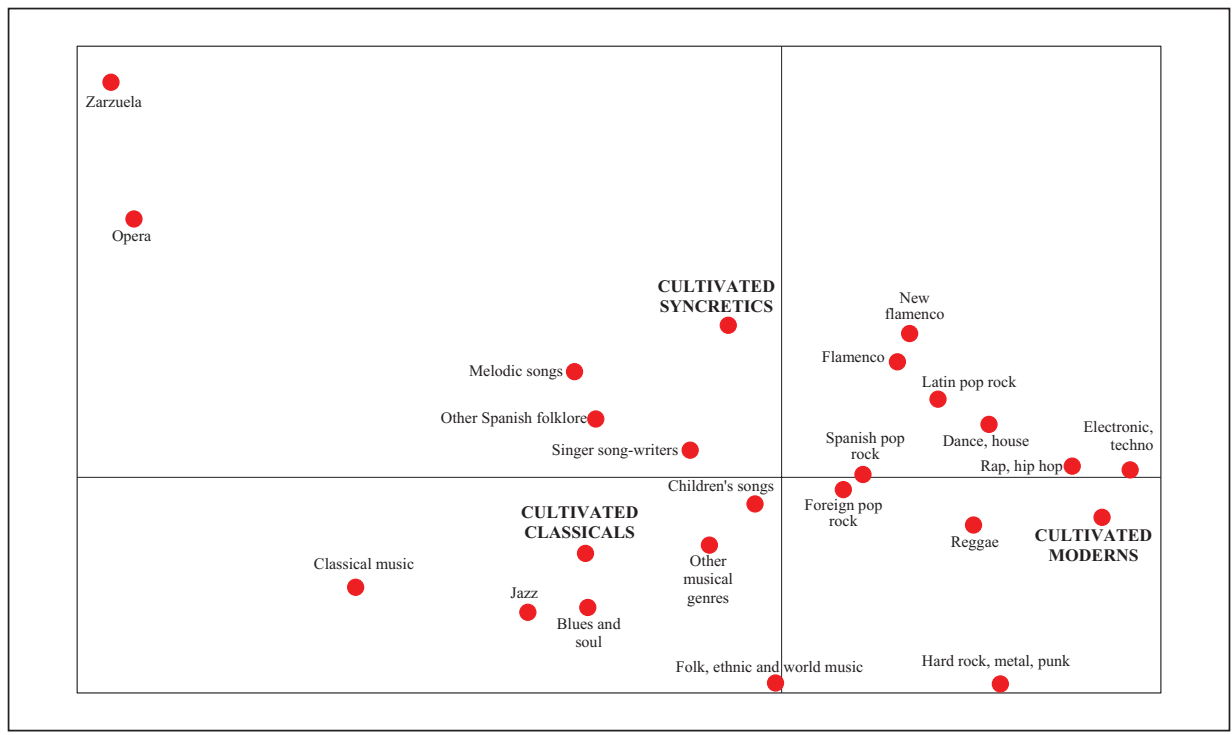

Figure I. Correspondence Analysis: musical genres associated to the three types of cultivated people.

and zarzuela. This also distinguishes them from the classicals and syncretics. The highest percentages are found both in different types of pop/rock and in more recent genres, ranging from techno music and rap or hip-hop to reggae or dance/ house.

- The cultivated classicals are represented by the much higher percentages in the taste for classical music, jazz, blues and world music. The difference is lower with syncretics in the case of opera. The lowest percentages are found in flamenco, whether it be traditional or modern.

- The cultivated syncretics present higher percentages than the rest of the population in almost all musical genres. Compared to the classicals they are distinguished by their greater connection with flamenco and zarzuela, and compared to the moderns their percentages are lower in what concerns their taste for hard rock, metal and punk, the genres, so to speak, that are more juvenile and hardcore.

The correspondence analysis, represented in Figure 1, shows the preferential association of the musical genres with the three types of cultivated people. In the lower hemisphere, but in different quadrants, we locate the classicals and moderns, while in the upper hemisphere, near the vertical axis, we observe the syncretics. Jazz, blues, soul and classical music surround the classicals. The moderns, instead, prefer techno-electronic, rap, hiphop and reggae. Around the syncretics, differentiated by the vertical axis, we find the melodic song, the singer-songwriters and other Spanish folklore, as well as flamenco and new flamenco. In a central position is pop and rock, while in an extreme, distant position is opera and zarzuela, derived from their constant audience loss. 
From this, we can conclude that the cultivated classicals and the moderns differ fundamentally by their positions around the horizontal axis, which contrasts classical and modern cultural tastes. The position of both clusters in relation to the vertical axis is practically identical, that is, slightly tilted towards a lower pole where international musical productions predominate. The cultivated syncretics, on the other hand, are much more indefinite in relation to the axis that contrasts the classical orientation with the modern one, although in the vertical axis they seem much more linked to the upper pole, characterized by musical preferences of a national character.

\section{Discussion and Conclusions}

We started with the assumption that there are diverse sociocultural profiles in the cultivated universe. The analyses carried out allow us to conclude that this population - initially defined both by the high volume of activities they enjoy and by their greater cultural interests in general - has a heterogeneous composition. In addition, they are much younger, have a higher level of education (more than twice the proportion of the general population) and are more often than the population as a whole working or studying.

This result converges with the plurality that Bourdieu registers with his multidimensional analysis of the social space; however, his typology and ours cannot be comparable, as we do not have the information about occupation and social class. This result also merges with cultural universes pointed out by Donnat; with Peterson's duality (snobs and omnivores); and with Lahire's variety. But, according to Bourdieu, the specific and fundamental logic that operates in the economy of cultural goods is legitimacy/illegitimacy; while for Peterson it is omnivority/univority; and for Lahire, dissonance/consonance. In Donnat, on the other hand, a diversity of logics appears and this approach has been highlighted by a wide literature (Benett et al., 2009; Chan, 2007; Friedman and Reeves, 2020; Lahire, 2004; Savage et al., 2015; Van Eijk, 2001).

The recognition of the plurality of logics cannot be resolved, as is sometimes done, by attempting to 'reconcile' or 'complement' Bourdieu's theory of distinction and Peterson's theory of omnivorousness (Lizardo and Skiles, 2016b). In our view, such a combination is impossible. Its unfeasibility is not only due to the very different degree of theoretical elaboration and empirical justification but above all, to the fact that it belongs to irreconcilable interpretative frameworks. Peterson moves in the tradition of the North American debates between elite/mass, with little theoretical foundation, description of strata and a substantialist approach, where the subjects choose freely and where each social class corresponds to a type of object and practice. Contrary to this, Bourdieu offers a complex theory of social fields, elaborate and relational, in which differences and distinctions are the result of relative positions within a field independent of the consciousness of subjects.

Certainly, omnivorousness has not been polished by Peterson and collaborators as a sociological concept; it has often been confused with eclecticism; it has been operationalized in very different and not always congruent ways and Peterson himself has recognized its instability. However, the concept of distinction has not been explicitly elaborated by Bourdieu either, and he has not constructed a sociocultural category from it as it could be that of 'the distinguished'. It does not follow that distinction and 
legitimacy are not operative and persistent logics in all societies. In fact, the empirical evidence on cultural inequalities is overwhelming (Bennet et al., 2009). Moreover, it shows that aesthetic dispositions are changing (Kahn, 2011) and that, even among the elites, other logics are present, such as the search for authenticity (Friedman and Reeves, 2020; Savage et al., 2015).

It is in this context that we propose the convenience of a more omni-comprehensive approach to the processes of description, categorization and analysis of tastes, in which terms such as eclecticism (as presented by Bourdieu, elaborated by Donnat and taken up again in Savage et al., 2015) or syncretism and others that may emerge, help to better interpret the complexity of the distribution of tastes and practices in any society. To this end, we propose the concept of cultural regime.

In the revision of the theoretical framework, we have seen that for Bourdieu and for more and more authors (Jarness, 2015; Lizardo and Skiles, 2016b; Savage et al., 2015), differentiation and distinction do not lie so much in the substantive and immutable properties of cultural objects, goods and practices, but rather in the mode of appropriation or use. For Bourdieu, this is precisely the emerging aesthetic disposition that operates in the tastes of freedom: in the capacity to interpret with formal codes what the popular classes, conditioned by their habitus and their lesser educational competences, prey to the taste of necessity, read in a substantive and naturalized key. If we accept this approach of Bourdieu, a good part of the interpretations that have been made of his theses are shown to be wrong, and at the same time, a very different understanding of the phenomena included in the so-called cultural omnivorousness emerges (Lizardo and Skiles, 2016b).

But is a cultivated aesthetic disposition, oriented towards distinction, the only possible rule in the use of cultural goods? Empirical research shows that there are others, and that they derive not only from class, but also from age and generation, sex and gender, ethnicity or religion, or other factors. However, research with survey data still gives very poor results, because as Bourdieu himself pointed out, 'it leaves out almost everything to do with the modality of practices' (Bourdieu,1984: 506).

Our empirical analysis has identified three types of cultivated relationships: classicals, moderns and syncretics. The first one is demographically more mature and has the highest educational level, while the second one is the youngest, with a high percentage of students, and the least educational capital. The third one combines classical and modern interests and show a greater isomorphism with the entire cultivated population, but, compared to the rest of the population, they are much younger and have more educational capital. This tripartite division can be related to the one that was found by Olivier Donnat, although we have decided to call the third type syncretics so as not to confuse them with the eclectic ones described byDonnat.

In addition to this, we have accomplished two analyses to capture the relationship of the different cultivated population in what refers to musical genres. The selection of these, from the wide repertoire of available activities, was based on the importance given to them by authors such as Bourdieu, Donnat, Peterson and many others, as well as on the possibility of comparing our results with this literature (Bennett et al., 2009; Coulangeon, 2005, 2013; Leguina et al., 2016; Prieur and Savage, 2013). 
The first analysis has allowed us to confirm a general fact: in all musical genres, with the exception of two (melodic music and other Spanish folklore) the scores of the cultivated profiles are higher than the average percentages of the rest of the population. This fact allows us to conclude that, in the musical field, if exclusive snobs do exist, as they have been described in the specialized literature, they would be a very small minority (Chan, 2019; Lahire, 2004; Savage et al., 2015; Wilensky, 1961). Although the increasingly ubiquitous nature of musical audition can be taken as a factor of the transformation of the logic of distinction, we have found that the three groups of cultivated people are distinguished from the rest and from each other. Their wide and renewed diversity does not prevent distinctions from operating in more subtle ways (Leguina e al., 2017).

The second analysis, based on the statistical technique of the correspondence analysis, has enabled us to outline the existence of two logics that produce enclaves, combinations and, in a certain manner, respond to different aesthetics: the first logic arises from the counterposition between classical tastes and modern tastes; the second from orientations of local-national character versus those of an international or cosmopolitan type. In the first, age and the historical moment are the key factors. Future research should focus more specifically on this issue, which has already been addressed by the theory of postmaterialism (Inglehart, 1977) and which has been studied extensively in the sociology of cultural participation (Bellavance, 2008; Christin et al., 2016; Donnat, 2011; Lizardo and Skiles, 2016b). The second logic can be understood in a musical market in which, both local-national and international genres, composers, groups and singers, operate successfully. We observed that the cultivated syncretics are more pro local-national genres, while both cultivated classicals (with jazz, blues, world music) and cultivated moderns (with foreign pop/rock, rap, reggae or hip-hop) are more inclined towards the prestige of international productions (Bellavance, 2008; Holt, 1997; Varriale, 2018).

The detection of these two logics, far from being a satisfactory finding, invites us to become aware of the need to study the rules that govern the practice modalities and the ways of appropriate objects, whether it be within personal cultural profiles or within group lifestyles. Such an analysis, first, should address -jointly and systematically- the variety of tastes, the number of activities and the combination of both. Second, it should describe the rules governing such combinations and explain the meaning of the action for the agents. This approach involves a study of cultural participation regimes which would require to be addressed using qualitative techniques.

Various authors have used terms that approximate this notion such as taste in Gans (1974) and Peterson (1992), universe in Donnat (2004) or mode in Friedman and Reeves (2020). The term 'regime' applied to a wide variety of contexts and, according to standard definitions, refers to the set of procedures, rules and institutions that govern a process, an organism or a thing. Boltanski, Thevenot and others have dealt with action regimes or d'engagement en l'action and understand by these the forms or modalities, based on principles of perception, that structure the actions and situations of the subjects (Boltanski and Thévenot, 1991). In the field of food, for example, in which the particular way in which an organism is nourished or fed is designated, we observe an explosion of modalities or different dietary regimes precisely as a consequence of the introduction of different rules that establish what we eat and what we exclude, how and why we eat what is included. 
The expression 'cultural regime' has been used with different meanings by Lizardo (2008), by Glevarec and Pinet (2009) and by Gayo-Cal (2015), but so far, there is no rigorous definition of the concept. Natalie Heinich, following pragmatic theory, has applied the term to examine the modalities of artistic production (1997).

We are aware of the need to continue in this direction, but in order to do so it may be of relevance to outline a concept. A regime of cultural participation, as a way of organizing - individually or in groups - cultural preferences and practices, will involve not only knowledge of cultural forms, genres, cultural goods and services, but also dispositions and interpretative skills so that certain activities can be selected on the basis of socially determined interests and preferences; this selection, conscious or unconscious, strategic, tactical or ordinary, will be based on rules that show both perception, appreciation and value for some genres and ignorance, lack of interest, indifference or aversion toward others. Each regime can organize the same set of 'ingredients' in very different ways depending on: content and or form; aesthetics and or utility; minority and or mass distribution. Subordination to status or social class should also be considered. Other logics, such as pleasure and personal cultivation, should not be excluded. As Bourdieu (1996: 16) stated, in the field of art 'the way things are done and the way they are talked about . . . often makes all the difference' and 'the same behavior or even the same good can appear distinguished to one person, pretentious to someone else and cheap or showy to yet another'. Recent research of underlying logics points in that direction (de Vries and Reeves, 2020; Lizardo, 2019; Pedersen et al., 2018; Van den Haack, 2018).

To conclude, some limitations of our study should be noted. First, we have based our research on data from the latest of the surveys of cultural habits and practices periodically carried out by the Ministry of Culture of the Government of Spain. The fact that this type of survey is designed to provide an empirical basis for cultural policies imposes serious limitations on the type of research that should be carried out to address the study of cultural participation regimes. Such an objective would require the development of an ad hoc questionnaire, which should be combined with other types of qualitative techniques that would allow a more in-depth study of the rules in addition to cultural assets and activities. This would allow access to the repertoire of tastes and practices of a particular individual and compare it with that of other individuals, something essential to advance in cultural research. It should be noted that authors cited in this article, such as Bourdieu, Lahire, Bellavance, Benett, Savage, and Miles, Jarness, and Friedman, have attempted to make these kinds of approaches, but have not yet developed a general theory of cultural participation regimes.

Another limitation of ministerial surveys lies in the way genres are determined (in this case, types of music). Their presentation in separate categories or the fusion of others in compact categories produces a rigidity that does not correspond to the real practice of the people and seems to grant them an immanent univocal meaning (Holt, 1997). An example of a practice of increasing success for collective moments of relaxation where different genres can be mixed is found in karaoke, which is not included in the survey (Peters et al., 2018).

Finally, the survey used has a specific limitation since it does not include sufficient information on the interviewee's occupational situation or on their income and income structure, which significantly limits the types of analysis to be carried out. However, 
through the educational level reached, an identification of those who occupy the higher sociocultural levels can be made, given the importance that educational capital has in the mature and highly stratified educational systems of the most advanced countries. In this sense, the results obtained are conclusive: the cultivated population is a population with a very high educational capital and belongs to the social elite in a broad sense.

\section{Note}

1. For further details on the EHPCE-2018/2019, see MCD (2019: 27-37).

\section{References}

Bellavance G (2008) Where's high? Who's low? What's new? Classification and stratification inside cultural 'Repertoire'. Poetics. Journal of Empirical Research on Culture, Media and the Arts 36(2-3): 189-216.

Bennett T, Savage M, Silva E, et al. (2009) Culture, Class and Distinction. London: Routledge. Blasius J, Lebaron F, Le Roux B, et al. (eds) (2019) Empirical Investigations of Social Space. Cham (Switzerland): Springer.

Boltanski L and Thévenot L (1991) De la justification. Les économies de la grandeur. Paris: Gallimard.

Bourdieu P (1968) Éléments d'une théorie sociologique de la perception artistique. Revue internationale des sciences sociales 20(4): 640-664.

Bourdieu P (1978) Les trois états du capital culturel. Actes de la recherche en sciences sociales 30: 3-6. DOI: https://doi.org/10.3406/arss.1979.2654.

Bourdieu P (1979) La distinction. Critique social du Jugement. Paris: Minuit.

Bourdieu P (1984) Distinction. Cambridge, MA: Harvard University Press.

Bourdieu P (1989) Social space and symbolic power. Sociological Theory 7(1):14-25.

Bourdieu P (1996) Physical Space, Social Space and Habitus. Institut for sosiologi og samfunnsgeografi, Universitetet i Oslo. Available at: https://archives.library.illinois.edu/ erec/University\%20Archives/2401001/Production_website/pages/StewardingExcellence/ Physical\%20Space,\%20Social\%20Space\%20and\%20Habitus.pdf (accessed 22 February 2021).

Bourdieu P and de Saint Martin M (1976) Anatomie du gout. Actes de la Recherche en Sciences Sociales 2(5): 2-81. DOI: https://doi.org/10.3406/arss.1976.3471.

Brisson R (2019) Back to the original omnivore: On the artefactual nature of Peterson's thesis of omnivorousness. Poetics 76: 101359. DOI: https://doi.org/10.1016/j.poetic.2019.03.004.

Chan TW (ed.) (2010) Social Status and Cultural Consumption. Cambridge: Cambridge University Press.

Chan TW (2019) Understanding cultural omnivores: Social and political attitudes. British Journal of Sociology 70(3):784-806.

Chan TW and Goldthorpe JH (2007) Social stratification and cultural consumption: The visual arts in England. Poetics 35: 168-190. DOI: https://doi.org/10.1016/j.poetic.2007.05.002.

Christin A, Coulangeon P and Donnat O (2016) Cultural participation, cohort effects, and higher education (1981-2012). Notes \& Documents 02. Available via: https://halshs.archivesouvertes.fr/halshs-01400391 (accessed 27 February 2021).

Coulangeon P (2003) La stratification sociale des goûts musicaux. Le modèle de la légitimité culturelle en question. Revue française de sociologie 44: 3-33. Available at: https://www. cairn.info/revue-francaise-de-sociologie-1-2003-1-page-3.htm (accessed 27 February 2021.

Coulangeon Ph (2005) Social stratification of musical tastes: Questioning the cultural legitimacy model. Revue française de sociologie 5(46): 123-154. 
Coulangeon $\mathrm{Ph}$ (2011) Les métamorphoses de la distinction. Inégalités culturelles dans la France d'aujourd'hui. Paris: Grasset.

Coulangeon P (2013) The omnivore and the 'class defector'. Musical taste and social mobility in contemporary France. Notes \& Documents 3 Sciences Po/CNRS: 1-21 halshs-00840790v2f.

Coulangeon Ph and Duval J (2014) The Routledge Companion to Bourdieu's 'Distinction'. London: Routledge.

Daenekindt S and Roose H (2014) Ways of preferring. Contrasting the 'what' and 'how' of cultural consumption. Journal of Consumer Culture 17(1): 25-45.

Denney R (1957) The Astonished Muse. Chicago, IL: Chicago University Press.

De Vries R and Reeves A (2020) What Does it Mean to Be a Cultural Omnivore? Conflicting Visions of Omnivorousness in Empirical Research. Working paper. SSRN (KAR id:80783). Available via: https://papers.ssrn.com/sol3/papers.cfm?abstract_id=3541022 (accessed 22 February, 2021).

Donnat O (1991) Démocratisation culturelle: la fin d'un mythe. Esprit 170(3/4): 65-82.

Donnat O (1994) Les français face a la culture. Paris: La Découverte.

Donnat O (2003) La question de la démocratisation dans la politique culturelle françise, Modern \& Contemporary France 11(1): 9-20.

Donnat O (2004) Les univers culturelles des français. Sociologies et societés 36(1): 87-103.

Donnat O (2011) Pratiques culturelles, 1973-2008: Dynamiques générationnelles et pesanteurs sociales. Culture Etudes 7: 1-7.

Donnat O and Cogneau D (1990) Les pratiques culturelles des français 1973-1989. Paris: La Découverte/La Documentation Française.

Friedman S and Reeves A (2019) From aristocratic to ordinary: Shifting modes of elite distinction. American Sociological Review 85(2): 323-350. DOI: https://doi.org/10.1177/00 03122420912941.

Friedman S, Savage M, Hanquinet L, et al. (2015) Cultural sociology and new forms of distinction. Poetics 53: 1-8. DOI: https://doi.org/10.1016/j.poetic.2015.10.002.

Flemmen MP, Jarness V and Rosenlund L (2019) Class and status: On the misconstrual of the conceptual distinction and a neo-Bourdieusian alternative. British Journal of Sociology 70(3): 816-866.

Friedman S and Reeves A (2020) From aristocratic to ordinary: Shifting modes of elite distinction. American Sociological Review 85(2): 323-350.

Gans H (1974) Popular Culture and High Culture. An Analysis and Evaluation of Taste. New York: Basic Books.

García-Álvarez E, Katz-Gerro T and López-Sintas J (2007) Deconstructing cultural omnivorousness 1982-2002: Heterology in Americans' musical preferences. Social Forces 86(2): $417-$ 443.

García Canclini N (1990) Culturas Hibridas. México: Grijalbo.

Gayo-Cal M (2015) Des régimes de distinction changeants: l'historicité de la consècration culturelle dans les goûts musicaux au Chili et Royaume-Uni. Regards Sociologiques 49: 108125.

Gayo-Cal M (2016) A critique of the omnivore. From the origin of the idea of omnivorousness to the Latin American experience. In: Hanquinet L and Savage M (eds) Routledge International Handbook of the Sociology of Art and Culture. London: Routledge, 104-114.

Glevarec H and Pinet M (2009) La 'tablature' des goûts musicaux: un modèle de structuration des préférences et des jugements. Revue Française de Sociologie 50(3): 599-640.

Glevarec H and Pinet (2017) Is cultural eclecticism axiological and a new mark of distinction? Cultural diversification and social differentiation of tastes in France. Cultural Sociology 11(2): 188-216. 
Grignon C and Passeron JC (1989) Le savant et le populaire. Miserabilisme et populisme en sociologie et en literature. Paris: Gallimard-Seuil.

Gruzinski S (1999) La Pensée métisse, Paris: Fayard.

Hair JF, Anderson RE, Tatham RL, et al. (1999) Análisis Multivariante. Madrid: Prentice Hall.

Heinich N (1997) L'amour de l'art en règime de singularité. Communications 64: 153-171. DOI: https://doi.org/10.3406/comm.

Holbrook M, Weiss M and Habich J (2002) Disentangling effacement, omnivore, and distinction effects on the consumption of cultural activities: An illustration. Marketing Letters 13: $345-357$.

Holt DB (1997) Distinction in America? Recovering Bourdieu's theory of taste from its critics. Poetics 25(2-3): 93-120.

Inglehart R (1977) The Silent Revolution: Changing Values and Political Styles Among Western Publics. Princeton, NJ: Princeton University Press.

Jarness V (2013) Class, status, closure: The Petropolis and cultural life. $\mathrm{PhD}$ thesis, Bergen: University of Bergen.

Jarness V (2015) Modes of consumption: From 'what' to 'how' in cultural stratification research. Poetics 53: 65-79.

Jarness V and Friedman S (2017) 'I'm not a snob, but. . .' Class boundaries and the downplaying of difference. Poetics 61: 14-25.

Johnston J and Bauman S (2007) Democracy versus distinction: A study of omnivorousness in gourmet food writing. American Journal of Sociology 113(1): 165-204.

Johnston J, Bauman S and Oleschuk M (2019) Omnivorousness, distinction or both? In: Wherry F and Woodward I (eds) The Oxford Handbook of Consumption. Oxford: Oxford University Press, 361-380.

Katz-Gerro T (2002) Highbrow cultural consumption and class distinction in Italy, Israel, West Germany, Sweden and the United States. Social Forces 8(1): 207-229.

Katz-Gerro T (2006) Comparative evidence of inequality in cultural preferences: Gender, class, and family status. Sociological Spectrum 26(1): 63-83.

Katz-Gerro T and Sullivan O (2010) Voracious cultural consumption: The intertwining of gender and social status. Time \& Society 19(2): 193-219.

Khan SR (2011) Privilege: The Making of an Adolescent Elite at St. Paul's School. Princeton, NJ: Princeton University Press.

Lahire B (2004) La culture des individus. Paris: Éditions la Decouverte.

Lahire B (2008) The individual and the mixing of genres: Cultural dissonance and self-distinction. Poetics 36(2-3): 166-188.

Lambert PS (2019) Class, status and lifestyle: On omnivores, distinction, and the measurement of social position. The British Journal of Sociology 70(3): 887-891.

Leguina A, Arancibia-Carvajal S and Widdop P (2017) Musical preferences and technologies: Contemporary material and symbolic distinctions criticized. Journal of Consumer Culture 17(2): 242-264.

Leguina A, Windop P and Tampabulon G (2016) The global omnivore: Identifying musical taste groups in Austria, England, Israel and Serbia. Sociological Research Online 21(3): 15, 1-17. DOI: https://doi.org/10.5153/sro.4020.

Lizardo O (2008) The question of culture and stratification revisited: A response to the comments. Sociologica 2: 1-8. DOI: 10.2383/27736.

Lizardo O (2014) Omnivorousness as the bridging of cultural holes: A measurement strategy. Theory and Society 43: 395-419. 
Lizardo O (2019) Specifying the 'what' and separating the 'how': Doings, sayings, codes and artifacts as the building blocks of institutions. In: Haack P, Sieweke J and Wessel L (eds) Microfoundations of Institutions. Research in the Sociology of Organizations 65A. Bingley: Emerald Publishing, 217-234.

Lizardo O and Skiles S (2013) Reconceptualizing and theorizing 'omnivorousness' genetic and relational mechanisms. Sociological Theory 30(4): 263-282.

Lizardo O and Skiles S (2016a) The end of symbolic exclusion? The rise of 'categorical tolerance' in the musical tastes of Americans: 1993-2012. Sociological Science 3: 85-108.

Lizardo O and Skiles S (2016b) After omnivorousness: Is Bourdieu still relevant? In: Hanquinet L and Savage M (eds) Handbook of the Sociology of Art and Culture. London: Routledge, 85-108.

Maguire JS (2016) Introduction. Looking at food practices and taste across the class divide. Food, Culture and Society 19(1):11-18.

MCD (2019) Encuesta de Hábitos y Prácticas Culturales en España 2018-2019. Madrid: Ministerio de Cultura y Deportes.

Ollivier M (2008) Modes of openness to cultural diversity: Humanist, populist, practical, and indifferent. Poetics 36(2-3): 120-147.

Ollivier M and Gautier G (2007) Cultural eclecticism: The example of television in Québec. Recherches sociographiques 48(1): 15-41.

Pedersen W, Jarness V and Flemmen M (2018) Revenge of the nerds: Cultural capital and the politics of lifestyle among adolescent elites. Poetics 70: 54-66.

Peters J, van Eijk CJM and Michael JM (2018) Secretly serious? Maintaining and crossing cultural boundaries in the karaoke bar through ironic consumption. Cultural Sociology 12(1): 58-74.

Peterson RA (1992) Understanding audience segmentation: From elite and mass to omnivore and univore. Poetics 21(4): 243-258.

Peterson RA (1997) The rise and fall of highbrow snobbery as a status marker. Poetics 25: 75-92.

Peterson RA (2002) Roll over Beethoven, there's a new way to be cool. Contexts 1(2): 34-39.

Peterson RA (2004) Le passage à des goûts omnivores: Notions, faits et perspectives. Sociologies et societés 30(1): 145-164.

Peterson RA (2005) Problems in comparative research. The example of omnivorousness. Poetics 33: 257-282.

Peterson RA and Kern RM (1996) Changing highbrow taste: From snob to omnivore. American Sociological Review 61(5): 900-907.

Peterson RA and Rossman G (2008) Changing arts audiences: Capitalizing on omnivorousness. In: Tepper SI and Ivey B (eds) Engaging Art: The Next Great Transformation of America's Cultural Life. New York: Routledge, 307-342.

Peterson RA and Simkus A (1992) How musical tastes mark occupational status groups. In: Lamont M and Fournier M (eds) Cultivating Differences: Symbolic Boundaries and the Making of Inequality. Chicago, IL: University of Chicago Press, 152-186.

Prieur A and Savage M (2013) Emerging forms of cultural capital. European Societies 15(2): 246-267.

Rossman G and Peterson RA (2015) The instability of omnivorous cultural taste over time. Poetics 52: $139-153$.

Roueff O and Robette N (2014) An eclectic eclecticisme: Methodological and theoretical issues about the quantification of cultural omnivorism. Poetics 47: 23-40.

Savage M, Cunningham N, Devine F, et al. (2015) Social Class in the 21st Century. London: Pelican. 
Van den Haak M (2018) High culture unravelled: A historical and empirical analysis of contrasting logics of cultural hierarchy. Human Figurations 7(1). Available at: http://hdl.handle. net/2027/spo.11217607.0007.108 (accessed 27 February 2021).

Van Eijck K (1999) Socialization, education, and lifestyle: How social mobility increases the cultural heterogeneity of status groups. Poetics 26: 309-328. DOI: https://doi.org/10.1016/ S0304-422X(99)00008-X.

Van Eijck K (2000) Richard A Peterson and the culture of consumption. Poetics 28: 207-224. DOI: https://doi.org/10.1016/S0304-422X(00)00022-X.

Van Eijck K (2001) Social differentiation in musical taste patterns. Social Forces 79(3): 1163 1185.

Van Rees K, Vermunt JK and Verboord M (1999) Cultural classifications under discussion. Latent class analysis of highbrow and lowbrow reading. Poetics 26(5-6): 349-365.

Varriale S (2018) Reconceptualizing aesthetic cosmopolitanism: Evidence from the early consecration of Anglo-American pop-rock in Italy. American Behavioral Scientist. DOI: https:// doi.org/10.1177/0002764218800139.

Warde A, Wright D and Gayo-Cal M (2007) Understanding cultural omnivorousness: Or, the myth of the cultural omnivore. Cultural Sociology 1(2): 143-164.

Wilensky HL (1961) The uneven distribution of leisure: The impact of economic growth on 'free time'. Social Problems 9(1): 32-56. DOI: https://doi.org/10.2307/799420.

\section{Author biographies}

Antonio Ariño Villarroya is a Sociology Professor at the University of Valencia (Spain). His substantive research interests include topics in cultural sociology and social theory. Among his books, some that stand out are: Prácticas culturales en España (Madrid, Ariel, 2010), La secesión de los ricos (Barcelona, Galaxia Gutemberg, 2016; with Joan Romero) and Culturas Abiertas, Culturas Críticas (Valencia, Tirant lo Blanch, 2019).

Ramon Llopis-Goig is a Sociology Professor at the University of Valencia (Spain). His substantive research interests include topics in sport and cultural participation. He has published extensively in academic journals as well as different books among which include Culturas en tránsito (Madrid, Fundación Autor, 2017; with Antonio Ariño) and Spanish Football and Social Change (London, Palgrave Macmillan, 2015).

\section{Appendixes}

Appendix I. Time performance frequencies included in the elaboration of the index of accumulated cultural participation.

\begin{tabular}{ll} 
Visit to a monument & Past year \\
Visit to archaeological site & Past year \\
Museum visit & Past year \\
Visit to an exhibition & Past year \\
Visit to an art gallery & Past year \\
Attendance at an archive & Past year \\
\hline
\end{tabular}


Appendix I. (Continued)

Reading books work/studies

Reading books for other reasons

Past year

Information press reading

Past year

Sports press reading

Daily

Reading of cultural magazines

Daily

Reading other magazines

Daily

Attendance at a library

Daily

Access to an online library

Past year

Past year

Attendance at the ballet or dance

Past year

Attendance to the opera

Past year

Attendance to the zarzuela

Past year

Theatre attendance

Past year

Attendance at classical music concert

Past year

Attendance at current music concert

Past year

Listening to music

Once a week

Attendance at the cinema

Past year

Film consumption

Once a week

Consumption of series

Once a week

Watching TV

Once a week

Listening to the radio

Computer use for work/studies

Once a week

Computer use for other reasons

Once a week

Once a week

Use of tablet for work/studies

Once a week

Using a tablet for other reasons

Once a week

Internet connection work/studies

Once a week

Internet connection for other reasons

Once a week

Attendance at the circus

Past year

Attendance at other stage performances

Past year

Attendance at cultural organizations

Past year

Attendance at conferences

Past year

Attendance at book fairs

Past year

Attendance at reading and creative writing clubs

Past year

Attendance at zoological parks

Past year

Attendance at botanical parks

Past year

Attendance at theme parks

Past year

Attendance at water parks

Past year

Attendance at fairground attractions

Past year

Attendance at fairs

Past year

Attendance at sporting events

Past year

Attendance at events of traditional culture or intangible heritage

Past year

Complementary training courses

Past year

Source: Own elaboration on EHPCE-2018/2019. 
Appendix 2. Index of accumulated cultural participation.

\begin{tabular}{|c|c|c|c|c|}
\hline Number of cultural activities & Frequency & $\%$ & Valid \% & Cumulative $\%$ \\
\hline 0 & 28 & 0.18 & 0.18 & 0.18 \\
\hline I & 312 & 2.02 & 2.02 & 2.20 \\
\hline 2 & 386 & 2.50 & 2.50 & 4.70 \\
\hline 3 & 451 & 2.92 & 2.92 & 7.62 \\
\hline 4 & 527 & 3.41 & 3.41 & 11.03 \\
\hline 5 & 622 & 4.02 & 4.02 & 15.05 \\
\hline 6 & 552 & 3.57 & 3.57 & 18.62 \\
\hline 7 & 599 & 3.88 & 3.88 & 22.50 \\
\hline 8 & 610 & 3.95 & 3.95 & 26.44 \\
\hline 9 & 631 & 4.08 & 4.08 & 30.53 \\
\hline 10 & 667 & 4.32 & 4.32 & 34.84 \\
\hline II & 665 & 4.30 & 4.30 & 39.15 \\
\hline 12 & 659 & 4.26 & 4.26 & 43.41 \\
\hline 13 & 650 & 4.21 & 4.21 & 47.62 \\
\hline 14 & 687 & 4.45 & 4.45 & 52.06 \\
\hline 15 & 655 & 4.24 & 4.24 & 56.30 \\
\hline 16 & 653 & 4.23 & 4.23 & 60.52 \\
\hline 17 & 642 & 4.15 & 4.15 & 64.68 \\
\hline 18 & 597 & 3.86 & 3.86 & 68.54 \\
\hline 19 & 563 & 3.64 & 3.64 & 72.18 \\
\hline 20 & 615 & 3.98 & 3.98 & 76.16 \\
\hline 21 & 529 & 3.42 & 3.42 & 79.59 \\
\hline 22 & 488 & 3.16 & 3.16 & 82.74 \\
\hline 23 & 422 & 2.73 & 2.73 & 85.47 \\
\hline 24 & 444 & 2.87 & 2.87 & 88.35 \\
\hline 25 & 375 & 2.43 & 2.43 & 90.77 \\
\hline 26 & 316 & 2.04 & 2.04 & 92.82 \\
\hline 27 & 254 & 1.64 & 1.64 & 94.46 \\
\hline 28 & 208 & 1.35 & 1.35 & 95.81 \\
\hline 29 & 190 & 1.23 & 1.23 & 97.04 \\
\hline 30 & 126 & 0.82 & 0.82 & 97.85 \\
\hline 31 & 95 & 0.61 & 0.61 & 98.47 \\
\hline 32 & 86 & 0.56 & 0.56 & 99.02 \\
\hline 33 & 51 & 0.33 & 0.33 & 99.35 \\
\hline 34 & 38 & 0.25 & 0.25 & 99.60 \\
\hline 35 & 18 & 0.12 & 0.12 & 99.72 \\
\hline 36 & 15 & 0.10 & 0.10 & 99.81 \\
\hline 37 & 12 & 0.08 & 0.08 & 99.89 \\
\hline 38 & 7 & 0.05 & 0.05 & 99.94 \\
\hline 39 & 5 & 0.03 & 0.03 & 99.97 \\
\hline 40 & 5 & 0.03 & 0.03 & 100.00 \\
\hline Total & 15,455 & 100.00 & 100.00 & \\
\hline
\end{tabular}

Source: Own elaboration on EHPCE-2018/2019. 
Appendix 3. Cultural Interests: Descriptive statistics.

\begin{tabular}{llllll}
\hline & $N$ & Minimum & Maximum & Mean & Std. deviation \\
\hline Reading in general & 15,455 & 0 & 10 & 6.50 & 2.731 \\
Reading books for work or study & 15,455 & 0 & 10 & 4.81 & 3.372 \\
Reading books for other reasons & 15,455 & 0 & 10 & 6.08 & 3.038 \\
Reading newspapers & 15,455 & 0 & 10 & 5.45 & 3.046 \\
Reading magazines & 15,455 & 0 & 10 & 4.21 & 2.969 \\
Libraries (attended or accessed via Internet) & 15,455 & 0 & 10 & 3.16 & 3.182 \\
Archive & 15,455 & 0 & 10 & 2.93 & 3.073 \\
Museums & 15,455 & 0 & 10 & 5.20 & 3.154 \\
Exhibitions & 15,455 & 0 & 10 & 4.84 & 3.130 \\
Art galleries & 15,455 & 0 & 10 & 4.16 & 3.178 \\
Historical monuments & 15,455 & 0 & 10 & 5.69 & 3.119 \\
Archaeological sites & 15,455 & 0 & 10 & 4.85 & 3.248 \\
Cinema and audiovisuals contents & 15,455 & 0 & 10 & 6.80 & 2.679 \\
Cinema in general & 15,455 & 0 & 10 & 6.70 & 2.792 \\
Audiovisuals contents & 15,455 & 0 & 10 & 6.97 & 2.562 \\
Performing arts in general & 15,455 & 0 & 10 & 5.32 & 2.983 \\
Theatre & 15,455 & 0 & 10 & 5.32 & 3.133 \\
Opera & 15,455 & 0 & 10 & 3.48 & 3.089 \\
Zarzuela & 15,455 & 0 & 10 & 3.19 & 2.988 \\
Ballet or dance & 15,455 & 0 & 10 & 3.79 & 3.168 \\
Circus & 15,455 & 0 & 10 & 3.91 & 3.019 \\
Music in general & 15,455 & 0 & 10 & 7.64 & 2.386 \\
Classical music concerts & 15,455 & 0 & 10 & 4.95 & 3.281 \\
Current music concerts & 15,455 & 0 & 10 & 6.56 & 2.939 \\
Listen to music & 15,455 & 0 & 10 & 7.75 & 2.373 \\
\hline & & & &
\end{tabular}

Source: Own elaboration on EHPCE-2018/2019.

Appendix 4. Cultural Interests of the 'cultivated' versus the rest of the population.

\begin{tabular}{lll}
\hline $\begin{array}{l}\text { Average scores }(0-10) \text { in } \\
\text { the different cultural } \\
\text { interests }\end{array}$ & $\begin{array}{l}\text { Cultivated population } \\
\text { (they carry out 22 and } \\
\text { more activities) }\end{array}$ & $\begin{array}{l}\text { Rest of population } \\
\text { (they carry out less } \\
\text { than 22 activities) }\end{array}$ \\
\hline Reading in general & 7.85 & 6.16 \\
Reading books for work or study & 7.06 & 4.24 \\
Reading books for other reasons & 7.68 & 5.67 \\
Reading newspapers & 6.60 & 5.16 \\
Reading magazines & 5.26 & 3.94 \\
Libraries (attended or accessed via internet) & 5.11 & 2.66 \\
Archive & 4.73 & 2.47 \\
Museums & 6.87 & 4.77 \\
Exhibitions & 6.68 & 4.36 \\
Art galleries & 5.83 & 3.73 \\
Historical monuments & 7.32 & 5.27 \\
Archaeological sites & 6.63 & 4.39 \\
Cinema and audiovisuals contents & 8.17 & 6.44 \\
\hline
\end{tabular}


Appendix 4. (Continued)

\begin{tabular}{lll}
\hline $\begin{array}{l}\text { Average scores }(0-10) \text { in } \\
\text { the different cultural } \\
\text { interests }\end{array}$ & $\begin{array}{l}\text { Cultivated population } \\
\text { (they carry out 22 and } \\
\text { more activities) }\end{array}$ & $\begin{array}{l}\text { Rest of population } \\
\text { (they carry out less } \\
\text { than 22 activities) }\end{array}$ \\
\hline Cinema in general & 8.13 & 6.33 \\
Audiovisuals contents & 8.22 & 6.65 \\
Performing arts in general & 6.93 & 4.91 \\
Theatre & 6.96 & 4.90 \\
Opera & 4.78 & 3.15 \\
Zarzuela & 3.96 & 2.99 \\
Ballet or dance & 5.09 & 3.45 \\
Circus & 4.87 & 3.67 \\
Music in general & 8.66 & 7.38 \\
Classical music concerts & 6.13 & 4.65 \\
Current music concerts & 7.99 & 6.19 \\
Listen to music & 8.88 & 7.46 \\
\hline
\end{tabular}

Source: Own elaboration on EHPCE-2018/2019.

Appendix 5. Rotated component matrix (cultural interests).

\begin{tabular}{|c|c|c|c|c|c|}
\hline & I & 2 & 3 & 4 & 5 \\
\hline Zarzuela & .834 & & & & \\
\hline Opera & .825 & & & & \\
\hline Ballet or dance & .796 & & & & \\
\hline Theatre & .680 & & & & \\
\hline Performing arts in general & .662 & & & & \\
\hline Classical concerts & .613 & & & & \\
\hline Circus & .556 & & & & \\
\hline Exhibitions & & .788 & & & \\
\hline Museum & & .787 & & & \\
\hline Archaeological sites & & .757 & & & \\
\hline Historical monuments & & .754 & & & \\
\hline Art galleries & & .744 & & & \\
\hline Archive & & .484 & & & \\
\hline Reading in general & & & .744 & & \\
\hline Reading books for other reasons & & & .717 & & \\
\hline Reading newspapers & & & .663 & & \\
\hline Reading magazines & & & .624 & & \\
\hline Reading books for work or study & & & .621 & & \\
\hline Libraries & & & .510 & & \\
\hline Cinema and audiovisuals in general & & & & .797 & \\
\hline Cinema & & & & .762 & \\
\hline Audiovisuals contents & & & & .754 & \\
\hline Listen to music & & & & & .824 \\
\hline Music in general & & & & & .795 \\
\hline Current music concerts & & & & & .770 \\
\hline Variance & $17.9 \%$ & $16.8 \%$ & $13.8 \%$ & $11.1 \%$ & $11.0 \%$ \\
\hline Cumulative Variance & $17.9 \%$ & $34.7 \%$ & $48.5 \%$ & $59.5 \%$ & $70.5 \%$ \\
\hline
\end{tabular}

Source: Own elaboration on EHPCE-2018/2019. 


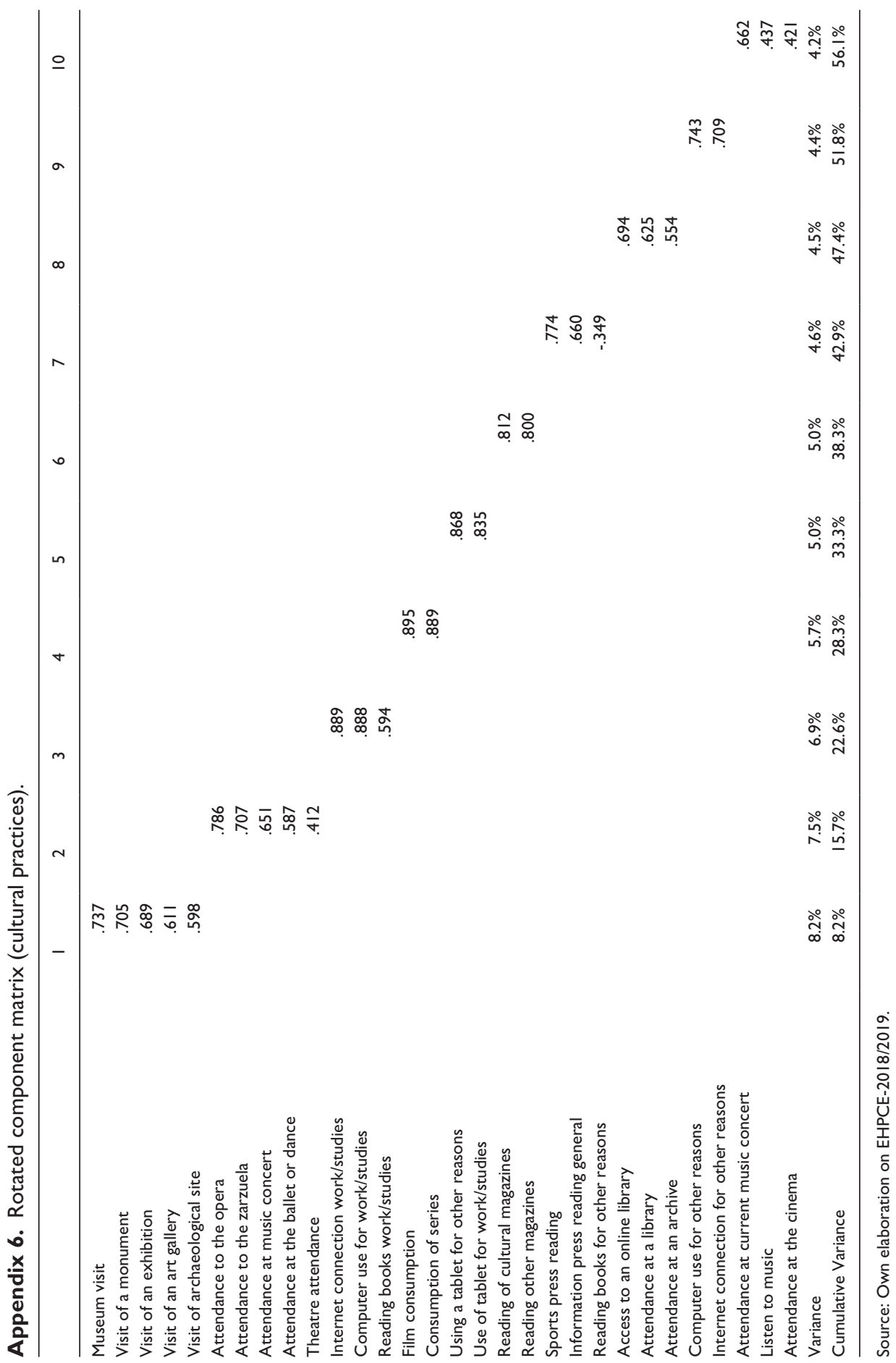

